Full length article

\title{
Development of an innervated tissue-engineered skin with human sensory neurons and Schwann cells differentiated from iPS cells
}

\author{
Quentin Muller $^{\mathrm{a}, \mathrm{b}, 1}$, Marie-Josée Beaudet ${ }^{\mathrm{a}, 1}$, Thiéry De Serres-Bérard ${ }^{\mathrm{a}}$, Sabrina Bellenfant ${ }^{\mathrm{a}}$, \\ Vincent Flacher ${ }^{\mathrm{b}}$, François Berthod ${ }^{\mathrm{a}, *}$ \\ ${ }^{a}$ Centre LOEX de l'Université Laval, Centre de recherche du CHU de Québec-UL, and Département de Chirurgie, Faculté de Médecine, Université Laval, Québec (Québec), Canada

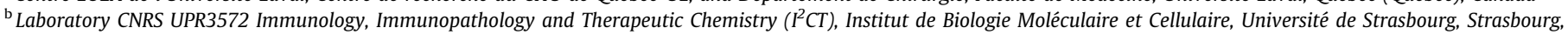 \\ France
}

\section{A R T I C L E I N F O}

\section{Article history:}

Received 6 June 2018

Received in revised form 25 September 2018

Accepted 9 October 2018

Available online 11 October 2018

\section{Keywords:}

Skin

Axonal migration

Substance P

CGRP

Induced pluripotent stem cells

TRPV1

\begin{abstract}
A B S T R A C T
Cutaneous innervation is increasingly recognized as a major element of skin physiopathology through the neurogenic inflammation driven by neuropeptides that are sensed by endothelial cells and the immune system. To investigate this process in vitro, models of innervated tissue-engineered skin (TES) were developed, yet exclusively with murine sensory neurons extracted from dorsal root ganglions. In order to build a fully human model of innervated TES, we used induced pluripotent stem cells (iPSC) generated from human skin fibroblasts. Nearly $100 \%$ of the iPSC differentiated into sensory neurons were shown to express the neuronal markers BRN3A and $\beta 3$-tubulin after 19 days of maturation. In addition, these cells were also positive to TRPV1 and neurofilament M, and some of them expressed Substance P, TrkA and TRPA1. When stimulated with molecules inducing neuropeptide release, iPSC-derived neurons released Substance P and CGRP, both in conventional monolayer culture and after seeding in a 3D fibroblastpopulated collagen sponge model. Schwann cells, the essential partners of neurons for function and axonal migration, were also successfully differentiated from human iPSC as shown by their expression of the markers S100, GFAP, p75 and SOX10. When cultured for one additional month in the TES model, iPSCderived neurons seeded at the bottom of the sponge formed a network of neurites spanning the whole TES up to the epidermis, but only when combined with mouse or iPSC-derived Schwann cells. This unique model of human innervated TES should be highly useful for the study of cutaneous neuroinflammation.
\end{abstract}

\section{Statement of Significance}

The purpose of this work was to develop in vitro an innovative fully human tissue-engineered skin enabling the investigation of the influence of cutaneous innervation on skin pathophysiology. To reach that aim, neurons were differentiated from human induced pluripotent stem cells (iPSCs) generated from normal human skin fibroblasts. This innervated tissue-engineered skin model will be the first one to show iPSC-derived neurons can be successfully used to build a 3D nerve network in vitro. Since innervation has been recently recognized to play a central role in many human skin diseases, such as psoriasis and atopic dermatitis, this construct promises to be at the forefront to model these diseases while using patient-derived cells.

(c) 2018 Acta Materialia Inc. Published by Elsevier Ltd. All rights reserved.

\footnotetext{
* Corresponding author at: Centre LOEX de l'Université Laval, Centre de recherche du CHU de Québec-UL, Hopital de l'Enfant-Jésus, Aile R, 1401, 18e rue, Québec (QC) G1J 1Z4, Canada.

E-mail address: francois.berthod@fmed.ulaval.ca (F. Berthod).

${ }^{1}$ Both authors contributed equally to the work.
}

\section{Introduction}

Although the primary purpose of cutaneous sensory innervation is the perception of sense of touch, pain and temperature, it also plays a major role in skin physiology and pathology. Indeed, sensory neurons are able to trigger a neurogenic inflammation upon stimulation through the release of neuropeptides. This process induces microvascular vasodilation and an increase in vascular permeability, along with immune cells chemotaxis and activation 
[1]. Consequently, neuronal triggering is intimately combined with the local innate immune response early after an injury to promote tissue inflammation. Moreover, it has more recently been shown that sensory neurons are also involved in the direct recognition of pathogens through the same molecular pathways as immune cells, such as Toll Like Receptors (TLRs) [2]. The density of cutaneous innervation as well as the high speed of neural action potentials constitute major advantages for the detection of danger signals. Thus, the in vitro development of a human skin integrating a nerve network represents an essential first step towards detailed studies on the interaction of nociceptor neurons with endothelial and immune cells and the regulation of neurogenic inflammation. We previously created an innervated TES including sensory neurons obtained from mouse embryos. These neurons were cultured underneath the tissue and were shown to build a dense nerve network that reached the epidermis through the whole thickness of the dermal compartment $[3,4]$. Neurons released neuropeptides such as SP that was shown to enhance reepithelialization in an in vitro model of wound healing [5]. Whereas murine neuropeptides successfully activated human cells, their animal origin in a human tissue-engineered skin model could be a limitation for further studies, all the more that dorsal root ganglion neurons are extracted at an early embryonic developmental stage (E12 to E14). To develop a more reliable innervated skin model, the use of human sensory neurons is highly desirable, especially for cosmetic research and development in Europe where the use of animal cells is banned.

Fortunately, the technology allowing the differentiation of neuronal cells from human skin fibroblasts induced to become pluripotent stem cells (iPSC) is now widely available [6].

Some research groups succeeded in differentiating iPSC into sensory neurons, albeit with low degrees of purity and cell yields, and these studies did not attempt to create tridimensional networks [7-14]. To study neurogenic inflammation, it is crucial that the sensory neurons differentiated from human iPS cells express the transient receptor potential cation channel subfamily (TRPV1, TRPV2, TRPV3, TRPA1) that regulate neuropeptides release [15]. Indeed, a challenge with hot temperature or irritant compounds like capsaicin or eugenol should drive activation of TRPVs and subsequent release of neuropeptides, mainly Substance P (SP) and Calcitonin gene-related peptide (CGRP), from peptidergic sensory neurons. Moreover, sensory neurons should express the tropomyosin receptor kinase A (TRKA) responsible for the binding to nerve growth factor (NGF), necessary for their survival [12].

Here, we propose a complete method to differentiate pure, functional sensory neurons and Schwann cells from human iPSCs and their combination in a 3D culture system to generate a fully human tissue-engineered skin model. It will be a highly valuable tool to study in vitro the relationship between human sensory nerves and skin physiopathology.

\section{Materials and methods}

\subsection{Cell culture}

All human cells used in this work were obtained with informed consent from the donors; The study was approved by the CHU de Quebec-Université Laval research ethics review board.

Fibroblasts and keratinocytes were isolated from human skin biopsies after breast reductive surgeries as previously described [16].

Human keratinocytes were cultured in flasks on a feeder layer of irradiated 3T3 mouse fibroblasts in DHc medium consisting of a 3:1 ratio of DMEM/Ham's F12 (Gibco, Gaithersburg, MD) with 36.54 mM NaHCO3 (J.T. Baker, Phillipsburg, NJ), 0.18 mM L-adenine
(Millipore Sigma, Oakville, Canada), $312.5 \mu \mathrm{l} / 12 \mathrm{~N}$ HCL (Fisher Scientific, Ottawa, Canada) and supplemented with $5 \%$ HyClone FetalClone II (Hyclone, Logan, UT), $2.5 \mu \mathrm{g} / \mathrm{mL}$ insulin (Millipore Sigma), $0.2 \mu \mathrm{g} / \mathrm{mL}$ hydrocortisone (Millipore Sigma), $10^{-10} \mathrm{M}$ cholera toxin (ICN Biochemicals, Costa Mesa, CA), $10 \mathrm{ng} / \mathrm{mL}$ human epidermal growth factor (Austral Biologicals, San Ramon, CA), and antibiotics.

Human microvascular endothelial cells were extracted from foreskin as previously described [17] and grown in endothelial growth medium EBM-2 (Lonza, Mississauga, Canada).

Mouse DRG were extracted from E12.5 mice as previously described [3] and cultured in DME medium (Gibco) supplemented with $10 \%$ fetal bovine serum (FBS) (Wisent, St-Bruno, Canada) and with $10 \mathrm{ng} / \mathrm{mL}$ NGF (Sino Biological, Atlanta, GA), and were cultured in same conditions as iPS-derived neurons to serve as controls. All animal experiments were approved by the CHU de Quebec-Université Laval animal care committee following the guidelines of the Canadian Council on Animal Care.

\subsection{Differentiation of iPS cells into sensory neurons:}

The iPS cells were obtained from the iPS-Quebec platform of the CHU de Québec-Université Laval research center. They were derived from 2 different human skin fibroblast cell lines and from one human peripheral blood mononuclear cell line. The iPS cells were reprogrammed with the CytoTune ${ }^{\mathrm{TM}}$-iPS 2.0 Sendai Reprogramming Kit (Invitrogen, Carlsbad, California).

Differentiation into sensory neurons was performed following a protocol modified from reference [14]: iPS cells were passaged with Stempro accutase (Gibco) added with $5 \mu \mathrm{M}$ Y-27632 (Abcam, Toronto, Canada), diluted in DMEM-F12 medium containing $25 \mu \mathrm{g} / \mathrm{ml}$ of penicillin-gentamycin (Sigma Chemicals) without serum. Cells were plated on Geltrex (Gibco) coating (1:200 dilution) in a 6 wells plate at a density of 90,000 cells $/ \mathrm{cm}^{2}$ and passaged at confluency with Stempro accutase and $5 \mu \mathrm{M}$ Y-27632. From day 0 to day 11 of differentiation, cells were cultured in a DMEM F12 : neurobasal A medium (Gibco) (vol:vol) supplemented with 2\% B-27 (Gibco), 1\% N2 supplement (Gibco), $0.01 \mathrm{mM}$ $\beta$-mercaptoethanol (Gibco), $50 \mu \mathrm{g} / \mathrm{mL}$ ascorbic acid (Sigma Millipore), $5 \mu \mathrm{M}$ Y-27632, $1 \%$ L-alanyl-L-glutamine (Corning, New-York, NY), 1\% MEM non-essential amino acids (Gibco), 0.1\% trace elements $A, 0,1 \%$ trace elements $B, 0,1 \%$ trace elements $C$ (Corning). From day 0 to day 5 of differentiation, medium was supplemented with $40 \mu \mathrm{M}$ SB431542, $0.2 \mu \mathrm{M}$ LDN193189 and $3 \mu \mathrm{M}$ CHIR99021 (Sigma Millipore). From day 5 to day 7 of differentiation, medium was supplemented with $3 \mu$ M CHIR99021. From day 9 to day 11 of differentiation, medium was supplemented with $10 \mu \mathrm{M}$ DAPT (Selleck Chemicals LLC, Houston, TX). At day 11, cells were passaged with Stempro accutase and $5 \mu \mathrm{M}$ Y-27632 and plated on $1 \mu \mathrm{g} / \mathrm{ml}$ Poly-D-lysine (Sigma Millipore) coated wells for 2D tests. Cells were seeded at 300,000 cells $/ \mathrm{cm}^{2}$ for purity tests, at 600,000 cells $/ \mathrm{cm}^{2}$ per well for ELISA tests and at $10^{6}$ cells $/ 3.6 \mathrm{~cm}^{2}$ when seeded over the 3D sponge model. For the quantification of the sensory neuron purity, cells were seeded on poly-D-lysine surface in a 24 -wells plate and the ratio of $\beta 3$ Tub/BRN3A positive cells versus the number of unstained but Dapi-positive cells at day 18 was quantified using an axio imager M2 microscope (Zeiss, Toronto, Canada). Experiment was done in sextuplicates and 6 fields per well were evaluated using a 40x lens.

\subsection{Differentiation of iPS cells into Schwann cells.}

Differentiation of iPSC into Schwann cells was performed following a protocol modified from reference [18]. Up to day 6, iPS cells were cultured in the same conditions than for sensory neuron differentiation in order to reach a neuronal precursor commitment. 
Then, cells were dissociated with accutase supplemented with $5 \mu \mathrm{M} \mathrm{Y}-27632$ and plated on a $9.6 \mathrm{~cm}^{2}$ Geltrex coated well ( $1: 200$ dilution in cold DH medium) at a density of 130,000 cells/ $\mathrm{cm}^{2}$ in the day 7 medium from sensory neuron differentiation. At day 7 , cells were cultured in minimum essential medium (STEMCELL Technologies, Vancouver, Canada) with 1\% N2 supplement, $1 \mathrm{mM} \beta$-mercaptoethanol, $5 \mu \mathrm{M}$ Y-27632, 1\% L-alanyl-L-glutamine, 1\% MEM non-essential amino acids (Gibco), 0.1\% trace elements A, $0.1 \%$ trace elements $\mathrm{B}, 0.1 \%$ trace elements $C$. From day 8 to day $11, \beta$-mercaptoethanol was removed and $35 \mathrm{ng} / \mathrm{ml}$ retinoic acid (Sigma Millipore) was added to the medium with $1 \%$ B27 supplement without vitamin A. At day 12, cells were passaged with accutase and plate on $1 \mu \mathrm{g} / \mathrm{ml}$ Poly-D-lysine coated well at a density of 50,000 cells $/ \mathrm{cm}^{2}$. From day 12 to day 26 , cells were cultured in STEMdiff Apel medium (STEMCELL Technologies) supplemented with $1 \% \mathrm{~N} 2$ supplement, $1 \% \mathrm{~B} 27$ supplement without vitamin $\mathrm{A}$, $5 \mu \mathrm{M}$ Y-27632, $5 \mu \mathrm{M}$ Y-27632, 1\% L-alanyl-L-glutamine, 1\% MEM non-essential amino acids, $0.1 \%$ trace elements $\mathrm{A}, 0.1 \%$ trace elements B, $0.1 \%$ trace elements C, $5 \mathrm{ng} / \mathrm{ml}$ PDGF-bb, (Gibco), $10 \mathrm{ng} / \mathrm{ml}$ BFGF (Feldan, Quebec City, Canada), $14 \mu \mathrm{M}$ forskolin (Sigma Millipore), $192 \mathrm{ng} / \mathrm{ml}$ NRG1 (R\&D System, Oakville, Canada). From day 26 until the end of the 2D culture, Schwann cells were maintained in DH medium supplemented with $10 \%$ FBS, $5 \mu \mathrm{M}$ forskolin, $50 \mathrm{ng} / \mathrm{ml}$ NRG1, $1 \%$ N2 supplement, $1 \%$ L-alanyl-t-glutamine. Schwann cells were cultured with $0.25 \mathrm{nM}$ goat anti-rabbit IgG (Electron microscopy sciences, Hatfield, PA) for 3 days before seeding cells on sponges [19]. For 2D coculture (Fig. 3D,H), 300,000 iPS Schwann cells were seeded with 600,00 iPS sensory neurons in 24-well plates. Cells were maintained in DMEM F12 : neurobasal A medium (vol:vol) supplemented with $1 \% \mathrm{~B}-27,1 \% \mathrm{~N} 2$ supplement, $50 \mu \mathrm{g} / \mathrm{mL}$ ascorbic acid, 1\% L-alanylL-glutamine, $20 \mathrm{ng} / \mathrm{mL}$ BDNF (Sino Biological), $10 \mathrm{ng} / \mathrm{mL}$ GDNF (Sino Biological) and $10 \mathrm{ng} / \mathrm{mL}$ NGF, $0.2 \mu \mathrm{g} \mathrm{ml} \mathrm{m}^{-1}$ hydrocortisone, $2.5 \mu \mathrm{g} \mathrm{ml}^{-1}$ insulin. Cells were cultivated 18 days before fixation.

\subsection{Cell purity quantification}

To quantify the proportion of iPS cells effectively differentiated into sensory neurons, neurons at day 11 were seeded at a density of 300,000 cells $/ \mathrm{cm}^{2}$ in 24 -wells plates on poly-D-lysine surface $(n=6)$ and cultured as previously described for 7 days. Cells were fixed with PFA $4 \%$ and cell purity was assessed using a Zeiss axio imager M2 microscope. Purity was determined by quantification of the ratio of $\beta 3 \mathrm{Tub} / \mathrm{BRN} 3 \mathrm{~A}$ positive cells compared to the number of Dapi-positive cells (Supplemental Fig. S2). For each well, 6 fields were evaluated using a 40x lens. The same method was performed for assessing Schwann cell purity by calculating the ratio of S100positive cells over the number of Dapi-positive cells.

\subsection{Preparation of the tissue-engineered 3D skin model}

Collagen sponges were prepared as previously described [20] and seeded with 800,000 human fibroblasts alone (for ELISA tests) or in combination with 800,000 endothelial cells (for all other conditions) and cultured in DME (Life Technologies) supplemented with $10 \%$ fetal calf serum (FCS) mixed 1:1 (vol:vol) with EBM2 (Lonza, Mississauga, Canada) and $50 \mu \mathrm{g} / \mathrm{mL}$ ascorbic acid for 7 days. Then, 400,000 fibroblasts (for ELISA tests) or in combination with 400,000 endothelial cells (for all other conditions) were seeded on the opposite side of the sponge. After 3 days, Schwann cells from mouse sciatic nerves [20] or derived from human iPSC were seeded (only when specified) at a density of 1 million per sponge on top of the sponge. All samples (with or without Schwann cells) were cultured for 7 days in DMEM-F12 medium supplemented with $10 \% \mathrm{FBS}, 5 \mu \mathrm{M}$ forskolin, $50 \mathrm{ng} / \mathrm{ml} \mathrm{NRG1,} \mathrm{1 \%} \mathrm{N2}$ supplement, $1 \%$ L-alanyl-L-glutamine.
One million of iPS-derived sensory neurons matured for 11 days were then seeded on the opposite side (versus Schwann cells) of the sponge and cultured for two days in DMEM F12:neurobasal A medium (vol:vol), supplemented with $1 \% \mathrm{~B}-27,1 \% \mathrm{~N} 2$ supplement, $50 \mu \mathrm{g} / \mathrm{mL}$ ascorbic acid, $5 \mu \mathrm{M} \mathrm{Y}-27632,10 \mu \mathrm{M}$ DAPT, $20 \mathrm{ng} / \mathrm{mL}$ BDNF (Feldan) and $10 \mathrm{ng} / \mathrm{mL}$ GDNF. The sponge was matured 6 additional days in DMEM F12, neurobasal A medium vol:vol, supplemented with $1 \% \mathrm{~B}-27,1 \% \mathrm{~N} 2$ supplement, $50 \mu \mathrm{g} / \mathrm{mL}$ ascorbic acid, $5 \mu \mathrm{M}$ Y-27632, $20 \mathrm{ng} / \mathrm{mL}$ BDNF (Sino Biological), $10 \mathrm{ng} / \mathrm{mL}$ GDNF (Sino Biological) and $10 \mathrm{ng} / \mathrm{mL}$ NGF.

Sponges were flipped upside down and 1 million of human keratinocytes were seeded on top of sponge (opposite side to neurons) under immersion in the culture medium. Samples were cultured 7 days in DMEM-F12 with 5\% Hyclone serum supplemented with $20 \mathrm{ng} / \mathrm{mL}$ BDNF (Feldan), $10 \mathrm{ng} / \mathrm{mL}$ GDNF, $10 \mathrm{ng} / \mathrm{mL}$ NGF, $50 \mu \mathrm{g} / \mathrm{mL}$ ascorbic acid, $0.2 \mu \mathrm{g} \mathrm{ml}^{-1}$ hydrocortisone, $2.5 \mu \mathrm{g} \mathrm{ml}^{-1}$ insulin, $10 \mathrm{ng} / \mathrm{mL}$ human epidermal growth factor and $10^{-10} \mathrm{M}$ cholera toxin. Then, sponges were lifted up at air-liquid interface to promote keratinocyte differentiation for 17 days in the same medium but without EGF.

\subsection{ELISA analyses}

To quantify SP and CGRP secretion with Elisa kit (Phoenix Pharmaceuticals), sensory neurons differentiated from iPSC or extracted from mouse DRG were seeded at a density of 600,000 and 300,000 cells $/ \mathrm{cm}^{2}$ respectively in 24 -well plates coated with poly-D-lysine. For ELISA quantification of the 3D tissue supernatants, sponges were seeded with 1 million sensory neurons derived from iPS or from DRG and were washed twice with DMEM-F12 without serum before treatment. For 2D or 3D tests, medium was replaced with $150 \mu \mathrm{l}$ or $400 \mu \mathrm{l}$ of DMEM-F12: Neurobasal A medium (vol:vol) pH 6.2, respectively. Capsaicin (Sigma Millipore) was dissolved in ethanol $99 \%$ for a final concentration of $10 \mu \mathrm{M}$. Cells were exposed with capsaicin or $\mathrm{KCl}$ (Fisher Chemical, Ottawa, Canada) for $5 \mathrm{~min}$ or with AITC (SigmaMillipore), eugenol (Sigma Millipore) or NGF for $10 \mathrm{~min}$ before removing the supernatant for Elisa tests or fixation with PFA $4 \%$ for immunostaining.

\subsection{Immunofluorescence}

Cells were fixed with $4 \%$ cold PFA for 20 min at $4{ }^{\circ} \mathrm{C}$, washed twice with cold phosphate-buffered saline (PBS) (composed of

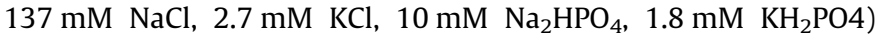
(Fisher Chemical), then incubated in immunofluorescence staining buffer, containing PBS, $0.3 \%$ triton X-100 (Biorad, Mississauga, Canada) and $5 \%$ serum, for $20 \mathrm{~min}$ at room temperature. Cells were stained overnight at $4{ }^{\circ} \mathrm{C}$ with primary antibodies diluted in immunofluorescence staining buffer and were washed with PBS for $5 \mathrm{~min}$ then incubated for $1 \mathrm{~h}$ at room temperature with secondary antibodies (1:500 dilution) in immunofluorescence staining buffer and finally were washed with PBS before mounting with fluoromount $G$ with Dapi (Electron microscopy Sciences, Hatfield, PA).

The antibodies used were: mouse anti- $\beta 3$ Tub (1:1000; Biolegend, San Diego, CA), rabbit anti-BRN3A (1:500; Millipore Sigma), mouse anti-substance P (1:1000; Abcam), goat anti-TRKA (1:200; R\&D System), rabbit anti-TRPA1 (1:200; Abcam), sheep antiTRPM8 (1:100; Novus Biologicals, Oakville, Canada), mouse or chicken anti-NFM and anti-NFH (1:500; Millipore Sigma), rabbit anti-TRPV1 (1:200; Novus Biologicals), goat anti-RAMP1 (1:50; Santa Cruz, Mississauga, Canada), rabbit anti-P75 (1:200; Abcam), rabbit or mouse anti-S100 (DAKO cytomation, Santa Clara, CA), mouse anti-MBP (1:500; R\&D System), mouse anti-SOX10 (1:500; R\&D System), mouse anti-GFAP (1:500; Millipore Sigma), 
rabbit anti-GFAP (1:1000; Abcam), Alexa fluor 488 goat anti-rabbit (1:500; Invitrogen), Alexa fluor 594 goat anti-mouse (1:500; Invitrogen), Alexa fluor 594 goat anti-rabbit (1:500; Invitrogen), Alexa fluor 488 goat anti-mouse (1:500; Invitrogen), Alexa fluor 647 donkey anti-sheep (1:500; Invitrogen), Alexa fluor 647 or 488 donkey anti-chicken (1:500; Invitrogen), Alexa fluor 555 donkey antimouse (1:500; Invitrogen), Alexa fluor 488 donkey anti-rabbit (1:500; Invitrogen).

\subsection{Statistical analysis}

Statistical analyses were performed using one-way ANOVA. Post-Hoc test were conducted using Bonferroni correction $(\alpha=0.05)$. The differences were considered significant at $\mathrm{p}<0.05$. Results were expressed as mean \pm standard error of the mean (SEM).

\section{Results}

3.1. Sensory neurons were differentiated from human iPS cells with high purity, high yield and expressed specific markers

Human fibroblasts-derived iPSCs cultured on Geltrex-coated 6well plates (2D culture) were allowed to differentiate for 22 days and were stained with specific markers for sensory neurons to confirm their identity. Based on the expression of BRN3A (a transcription factor expressed in the developing sensory neurons [21,22], neurofilament M (NFM, $150 \mathrm{kDa}$ [23]) and TRPV1, the optimal maturation time was observed at day 19, and was followed by a decrease in the number of cells at day 22 (Supplemental Fig. S1A-O). Mouse dorsal root ganglion (DRG)-derived sensory neurons expressed the same markers in a similar pattern (Supplemental Fig. S1P-R).

To determine the proportion of iPS-derived cells that were efficiently differentiated into sensory neurons, cells were doublestained for BRN3A, and $\beta 3$ Tub (staining for $\beta I I I-t u b u l i n$, a generic marker of neurons [24]). Immunfluorescence images showed that nearly $100 \%(98.9 \% \pm 1.35, n=6)$ of cells were positive for both markers (Supplemental Fig. S2). Over the whole maturation period, iPSC growth resulted in a $65 \pm 15$-fold increase $(n=10)$ in the number of cells differentiated into sensory neurons, as compared to the initial number of iPSC seeded. This high yield, as compared to the original protocol by Maury et al. [14] might be explained at least in part by a more potent growth of cells as monolayer culture instead of neurospheres. Moreover, the culture medium was supplemented by additional nutrients. And accutase, a mild digestive enzyme, was used instead of trypsin, allowing a more efficient cell recovery for cell harvesting/replating.

At day 19 , in addition to BRN3A and $\beta 3$ Tub, some of the differentiated cells expressed the neurofilament $M$ and SP. In addition, most cells were positive to TRPV1 and TRPA1, with some of them expressing TrkA (the receptor for NGF) (Fig. 1A,C,E,G).

To incorporate the iPSC-derived neurons into the 3D model, it was not possible to first fully differentiate the neurons in 2D for 19 days, and then seed them over the sponge. Indeed, since mature neurons already displayed long neurites at day 19 , their enzymatic digestion induced massive cell death precluding their use for $3 \mathrm{D}$ seeding. To overcome this limitation, iPSC-derived neurons were passaged with accutase at day 11 of differentiation (before neurite outgrowth) and seeded on the sponge 3D model. To confirm that the differentiation of the sensory neurons between day 11 and day 19 was as efficient in 3D as in 2D, the expression of neuronal markers was assessed by immunofluorescent staining of whole sponges, followed by en-face imaging. A similar pattern of expression of the markers BRN3A, $\beta 3$ Tub, SP, NFM, TrkA and TRPA1 was observed, along with Ramp1 (a CGRP receptor) (Fig. 1B,D,F,H).

In addition, since these neurons can be maintained in $3 \mathrm{D}$ culture for a much longer time, numerous nerve fibers were observed after 49 days of culture to express the neurofilament $\mathrm{H}(200 \mathrm{kDa})$, which is a marker of larger caliber and more mature axons [25]. In addition, most of these NFH-positive fibers also expressed SP (Supplemental Fig. S3).

Interestingly, iPSC-derived neurons showed a tendency to aggregate together into ganglion-like clusters from which large bundles of neurites elongated, in contrast with mouse DRG neurons that were homogeneously distributed beneath the sponge (Fig. 1I,J). Of note, a similar cluster formation was reported with iPSC-derived sensory neurons cultured in 2D after 2 weeks in culture [26]. The non-peptidergic marker P2X3 was not detected in 2D and 3D cultures (Data not shown).

\subsection{TRP agonists trigger SP and CGRP release from iPSC-derived sensory neurons}

In order to test the capacity of the iPSC-derived sensory neurons to induce neurogenic inflammation, their potential to release neuropeptides upon TRPV activation was investigated and compared to mouse DRG neurons in conventional 2D culture as well as in $3 \mathrm{D}$ culture into the sponge (only populated with fibroblasts).

The TRPV1 agonists resiniferatoxin (at $100 \mathrm{nM}$ ) induced a significant increase in the release of SP from iPSC-derived neurons cultured in 2D compared to control ( $p<0.0001 ; n=13)$, while the effect of capsaicin (at $10 \mu \mathrm{M}$ ) was not significant (Fig. 2A). Moreover, eugenol (at $1 \mathrm{mM}$ ), an agonist of TRPV1, 2 and 3 induced a significant increase of SP release $(p<0.0001 ; n=14)$, as well as NGF (at $100 \mathrm{ng} / \mathrm{ml}$ ), the agonist of TrkA ( $<<0.01 ; \mathrm{n}=16$ ). $\mathrm{KCl}$ (at $65 \mathrm{mM}$ ), which induces neuronal depolarization independently of receptors, promoted the most potent rise of SP release $(\mathrm{p}<0.0001 ; \mathrm{n}=16)$ (Fig. 2A). Of note, although TRPA1 was detected by immunofluorescence staining, exposure to its agonist AITC $(300 \mu \mathrm{M})$ did not result in a significant difference of SP secretion. As a control, 2D culture of mouse DRG neurons showed significant increases of SP release upon stimulation with capsaicin $(\mathrm{p}<0.0001 ; \mathrm{n}=5)$, resiniferatoxin $(\mathrm{p}<0.0001 ; \mathrm{n}=6)$, eugenol $(\mathrm{p}<0.01 ; \mathrm{n}=6)$ and treatment with $\mathrm{KCL}(\mathrm{p}<0.0001 ; \mathrm{n}=6)$ (Fig. 2B).

When cultured in 3D in a fibroblast-populated sponge, iPSCderived neurons released significantly higher amount of SP after stimulation with capsaicin $(\mathrm{p}<0.0001 ; \mathrm{n}=17)$ and $\mathrm{KCl}$ $(\mathrm{p}<0.001 ; \mathrm{n}=16)$, while resiniferatoxin, AITC and NGF did not have an effect (Fig. 2C). Stimulation of mouse DRG neurons in the same 3D culture scaffold produced significantly higher levels of SP upon treatment with capsaicin $(\mathrm{p}<0.01 ; n=6)$, resiniferatoxin ( $\mathrm{p}<0.001 ; \mathrm{n}=5)$ and $\mathrm{KCl}(\mathrm{p}<0.0001 ; \mathrm{n}=7)$ (Fig. 2D).

The secretion of CGRP by iPSC-derived neurons was significantly enhanced by eugenol $(\mathrm{p}<0.0001 ; \mathrm{n}=18)$, AITC $(\mathrm{p}<0.001$; $\mathrm{n}=18), \mathrm{NGF}(\mathrm{p}<0.001 ; \mathrm{n}=18)$ and $\mathrm{KCl}(\mathrm{p}<0.01 ; \mathrm{n}=18)$ in 2D culture (Fig. 2E), and by eugenol $(\mathrm{p}<0.0001 ; \mathrm{n}=11)$ and $\mathrm{KCl}$ $(\mathrm{p}<0.001 ; \mathrm{n}=17)$ in 3D sponges (Fig. 2G). Mouse DRG neurons released significantly more CGRP upon stimulation with eugenol $(\mathrm{p}<0.0001 ; \mathrm{n}=7)$, capsaicin $(\mathrm{p}<0.01 ; \mathrm{n}=11)$ and resiniferatoxin $(\mathrm{p}<0.01 ; \mathrm{n}=11)$ in 2D (Fig. 2F) and capsaicin $(\mathrm{p}<0.0001$; $\mathrm{n}=21)$, resiniferatoxin $(\mathrm{p}<0.0001 ; \mathrm{n}=6)$ and $\mathrm{KCl}(\mathrm{p}<0.0001$; $\mathrm{n}=7$ ) in 3D (Fig. 2H).

The capacity of capsaicin to induce an action potential in iPSCderived neurons was confirmed by the quantification of calcium entry into cells upon stimulation. Five seconds after addition of $10 \mu \mathrm{M}$ of capsaicin in the culture medium, an increase by $30 \%$ of the relative fluorescence intensity was observed in iPSC-derived neurons compared to the non-stimulated condition, which went 

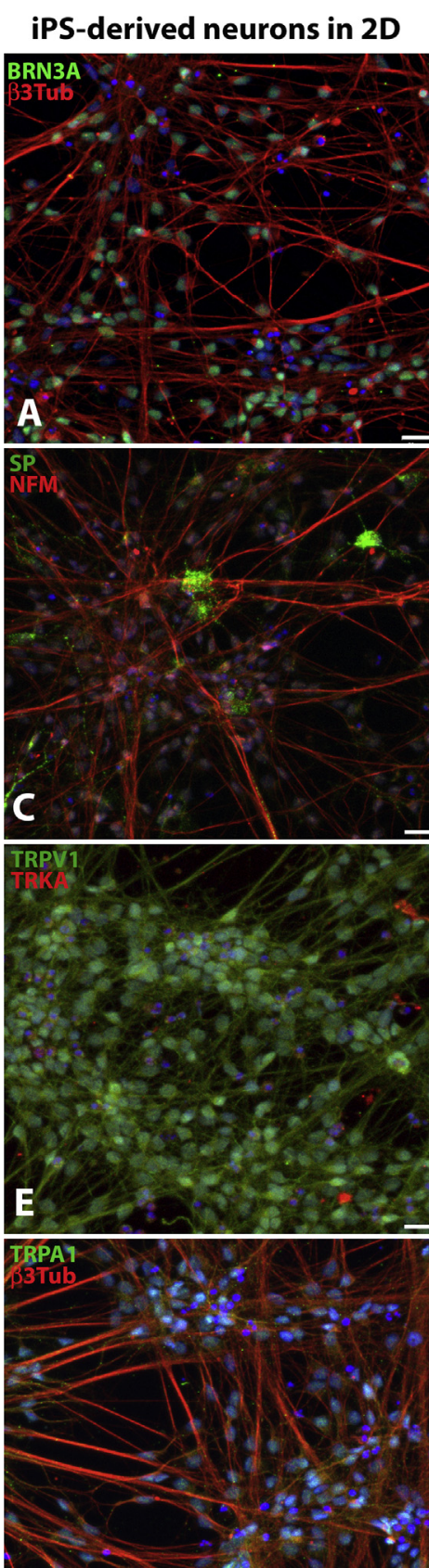

TRPA

G
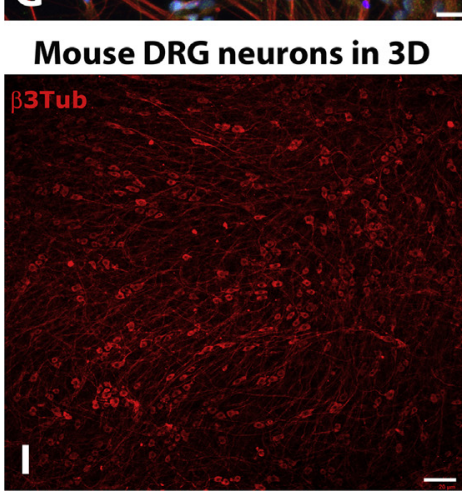

\section{iPS-derived neurons in 3D}

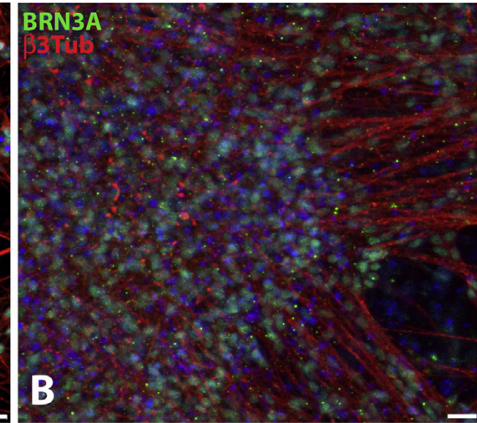

SP
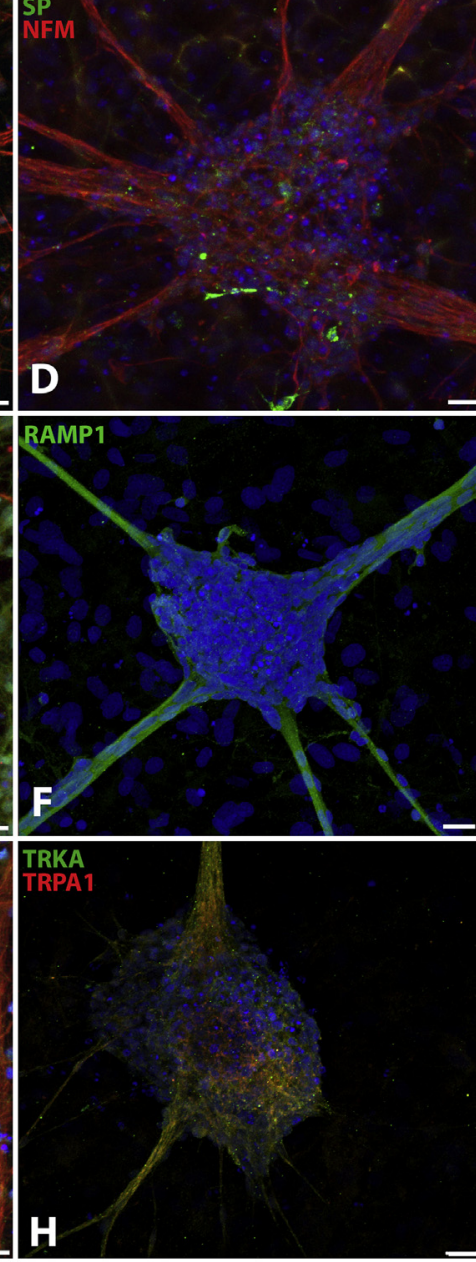

iPS-derived neurons in 3D

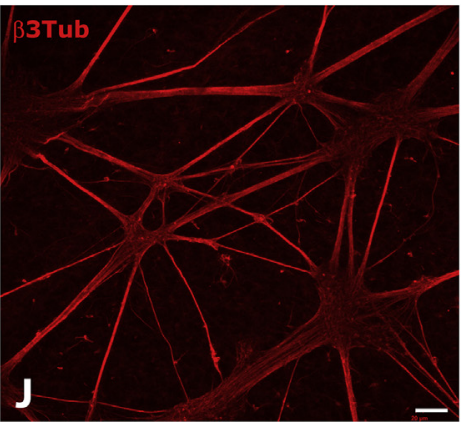

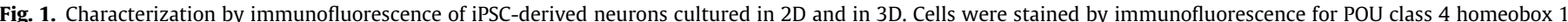

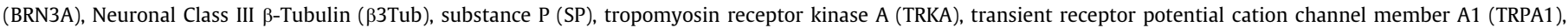

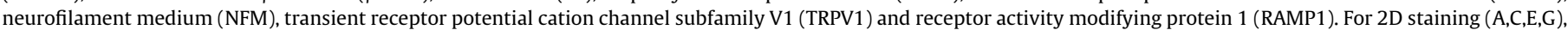

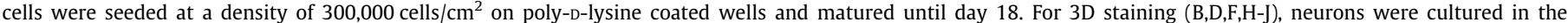
fibroblast-populated sponge for 19 days and pictures were taken from an above view of the sponge. Scale bar A-H $=20 \mu \mathrm{m}, \mathrm{I}-\mathrm{J}=100 \mu \mathrm{m}$. 


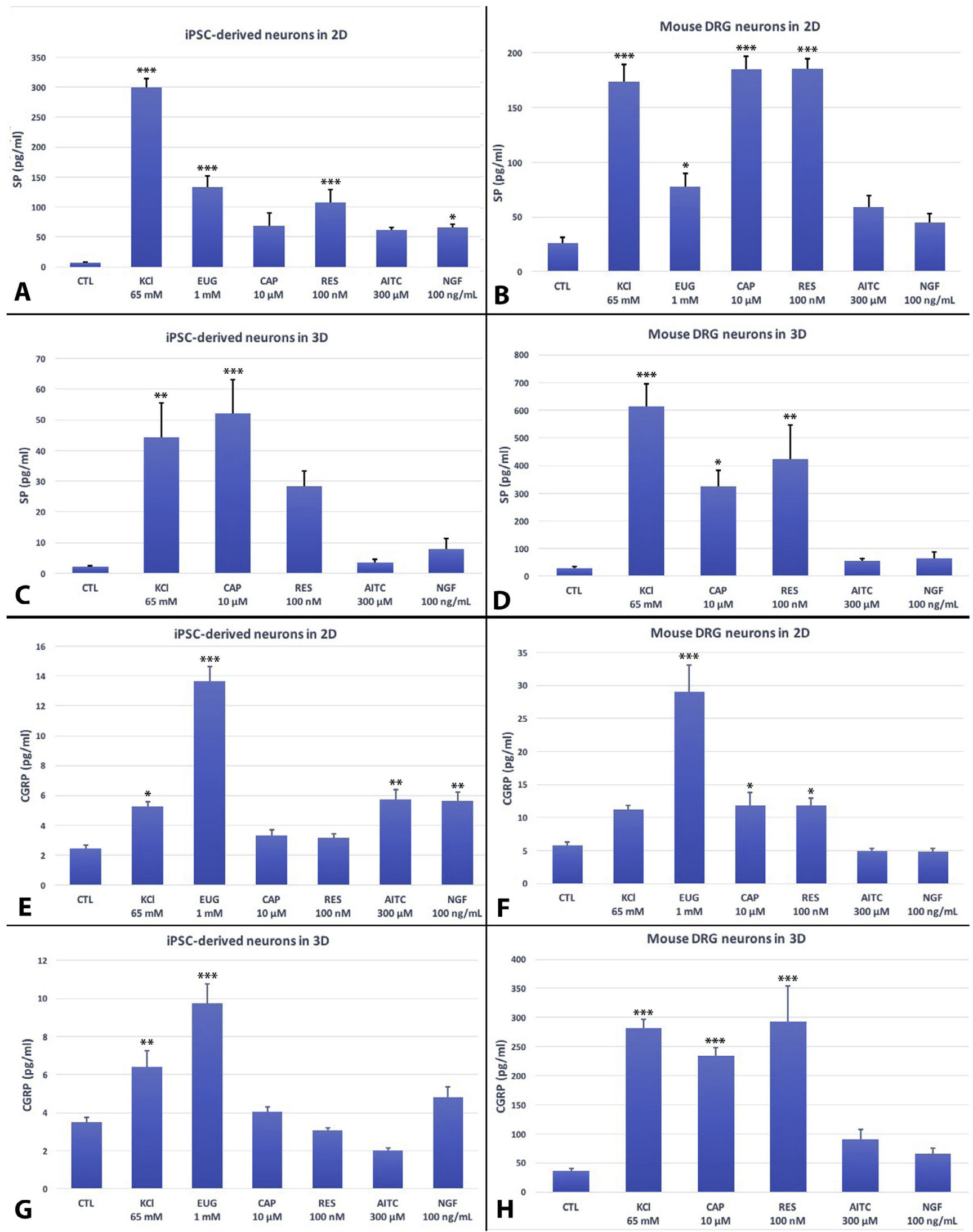

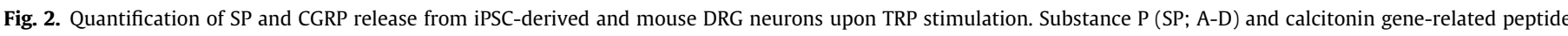

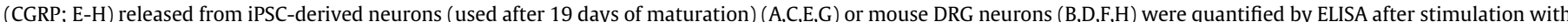

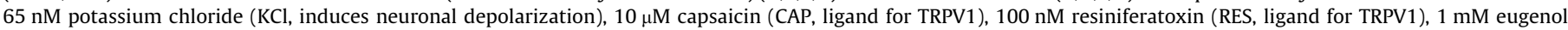

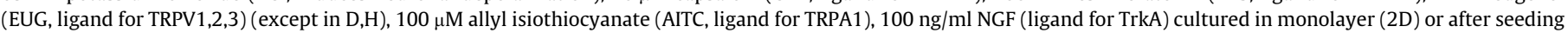
in a fibroblast-populated sponge (3D). Data are displayed as mean \pm standard error of the mean $\left({ }^{*} \mathrm{p}<0.01 ;{ }^{* *} \mathrm{p}<0.001 ;{ }^{* * *} \mathrm{p}<0.0001, \mathrm{n}=5\right.$ to 21$)$. 

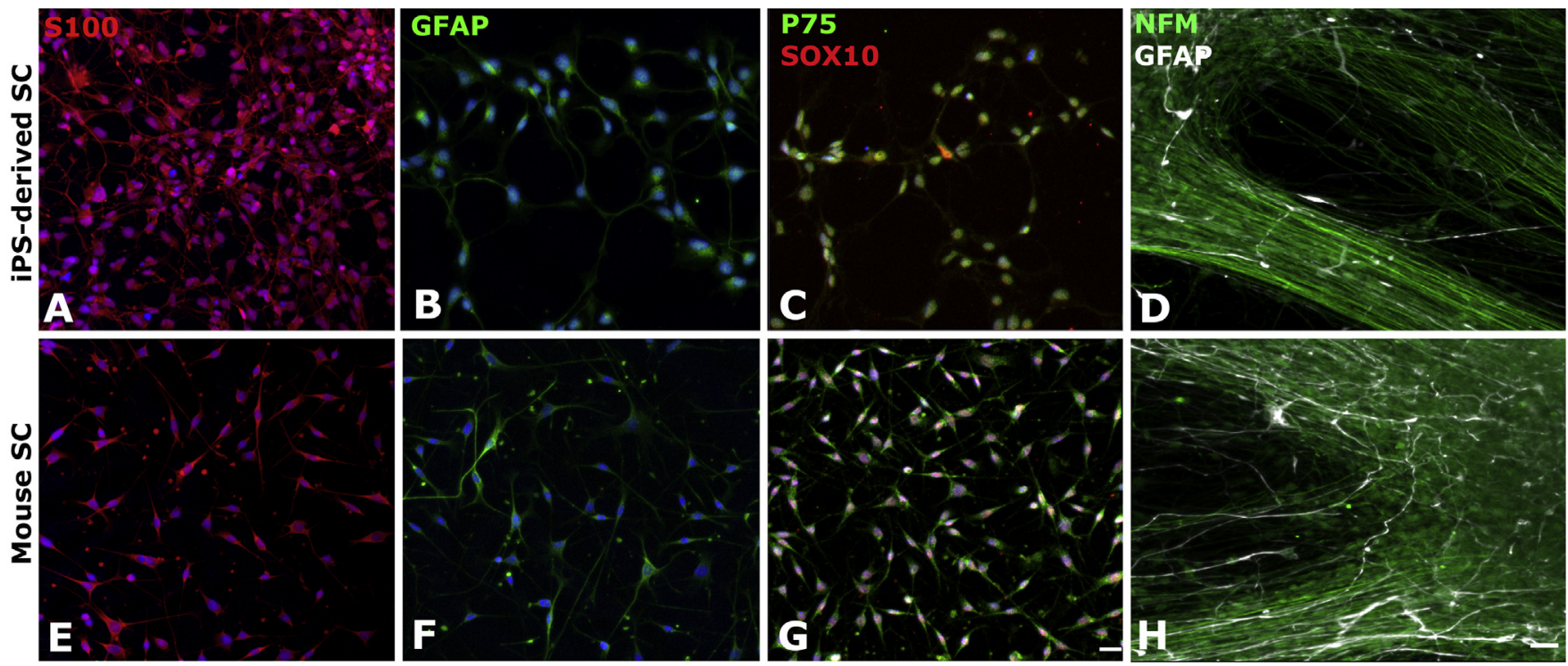

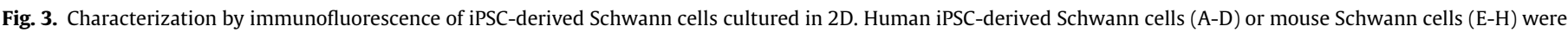

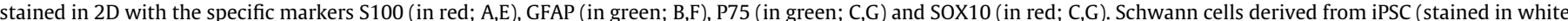

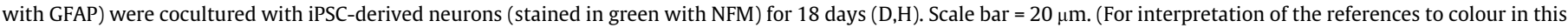
figure legend, the reader is referred to the web version of this article.)

back to initial values after $5 \mathrm{~s}$ (Supplemental Fig. S4). The fibroblasts used to generate iPSC did not show any increase in calcium upon capsaicin stimulation (Data not shown).

\subsection{Efficient neurite outgrowth from iPSC-derived neurons throughout the tissue-engineered skin is dependent on the presence of mouse or iPSC-derived Schwann cells}

When iPSC-derived neurons were cultured in the tissueengineered skin model, they failed to promote axonal outgrowth from the neuronal cell layer at the bottom of the tissue to the epidermis on top as observed with mouse DRG neurons (Fig. 4B vs A). One major difference with DRG neurons that could explain this limitation is the presence of Schwann cells that are extracted from DRG along with neurons. Thus, we hypothesized that Schwann cells might be an essential partner to promote axonal outgrowth. Indeed, when mouse Schwann cells were added in the tissueengineered skin model prior to iPSC-derived neuron seeding, a much higher neurite outgrowth was observed in the tissue with numerous axons reaching the epidermis (Fig. 4C).

In order to develop a fully human model, the same iPSC used to generate neurons were differentiated into human Schwann cells. The resulting human iPSC-derived Schwann cells expressed the specific markers S100, GFAP, p75 and SOX10 (Fig. 3). When these cells were added in a 2D culture of iPSC-derived neurons, they aligned along the neurites as observed with mouse Schwann cells (Fig. 3D vs H). When the iPSC-derived Schwann cells were added in the dermal compartment of the tissue-engineered skin model before seeding and at the opposite side versus neurons, they were shown to induce a strong increase in axonal outgrowth toward the epidermis (Fig. 4D).

\section{Discussion}

The aim of this work was to generate human iPSC-derived sensory neurons to be used in place of rodent neurons to prepare innervated tissue-engineered skin models. The animal origin of neurons in these models does not seem to critically compromise their ability to interact with most human skin cells, notably because neuropeptides are highly conserved among species. However, interspecies differences cannot be ruled out. Finally, the use of animal cells has been banned in the European Union for cosmetic research and development. Therefore, the replacement of animal neurons by human neurons remains highly desirable.

Since the advent of the iPSC technology, several protocols have been proposed to differentiate human sensory neurons from iPSC, but with some limitations, such as low neuron differentiation efficiency and low cell yields [7-14]. Moreover, none of these studies have unequivocally demonstrated the ability of these neurons to secrete neuropeptides following specific stimulations. Our purpose was to generate sensory neurons from human skin fibroblastderived iPSC with high purity, high yield, and to demonstrate their capacity to release SP and CGRP upon stimulation of their TRP receptors.

In addition, we showed that these iPSC-derived neurons could be efficiently integrated into a 3D tissue-engineered skin model. Interestingly, this culture system created a favorable environment for prolonged neuronal culture (49 days vs. 21 days in 2D), thereby allowing the neurons to reach a higher maturation stage in $3 \mathrm{D}$ while maintaining their capacity to release neuropeptides upon stimulation. Moreover, a key feature of a functional innervated tissue-engineered skin model is the ability of neurites extending from neurons seeded at the bottom of the tissue to migrate through the dermal compartment and form a nerve network reaching the epidermis. Indeed, a direct contact of neurites with keratinocytes is essential to efficiently recapitulate skin physiopathology. A key finding of our work is the demonstration that a coculture of iPSC-derived neurons with Schwann cells was necessary to induce a strong neurite outgrowth in 3D. Of note, human Schwann cells differentiated from the same iPSC used to generate neurons were able to support such neurite outgrowth to maintain a fully human model. It represents a promising method for generate a fully human innervated tissue-engineered skin model from the biopsy of a single individual.

We intend to develop disease-specific skin models and analyze the potential effect of sensory nerves in these models after induction of neuropeptide release upon stimulation with TRPV1 agonists. Such model would be particularly well-suited for the modelling of psoriasis, since this disease is highly suspected to 

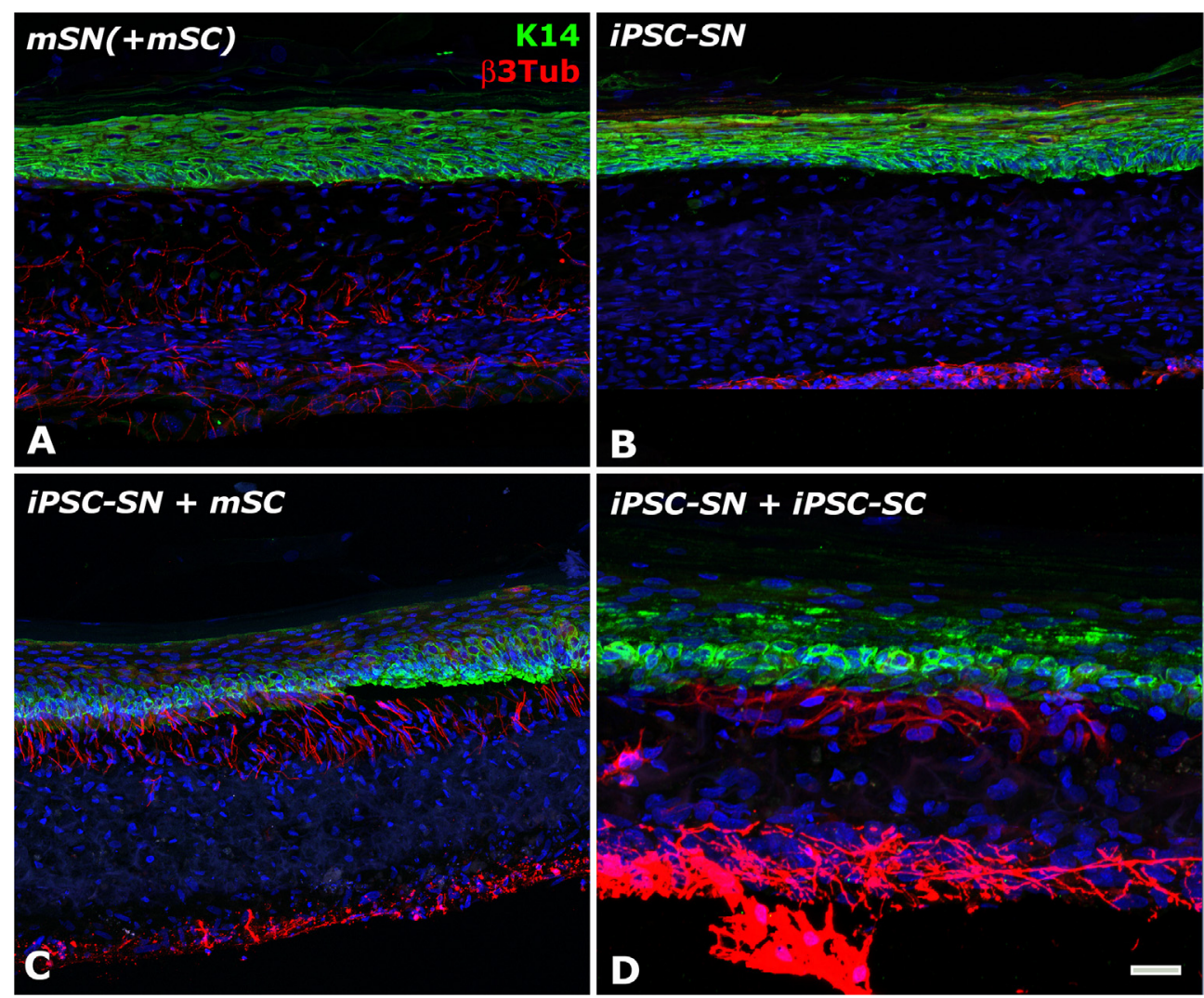

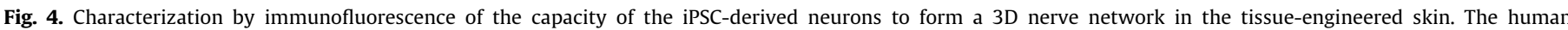

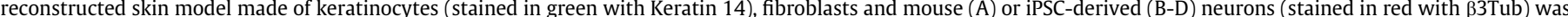

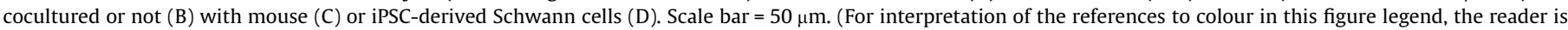
referred to the web version of this article.)

be modulated by skin innervation $[27,28]$. It represents an optimal base to build an immunocompetent skin model, with a strong potential for personalized medicine approaches.

\section{Declaration of interest}

None.

\section{Author contribution}

QM and M-JB contributed to the conception, design and achievement of experiments.

TDSB and SB participated to the acquisition of data.

VF participated in interpretation of data and critically revised the article.

FB contributed to the study conception and design, analysis of data, drafting of the article and gave final approval of the submitted version.

\section{Acknowledgments}

The authors acknowledge Dr. Jack Puymirat and the iPS-Quebec platform of the CHU de Québec-Université Laval research center for the production of the human iPS cell lines used in this work.

Funding: This work was supported by the CQDM (Centre Québécois pour la Découverte du Médicament), Pierre Fabre Dermocosmétique (Toulouse, France) and the Quebec Network for Cell and Tissue Therapies - ThéCell (a thematic network supported by the Fonds de recherche du Québec-Santé). QM and VF were supported by Région Alsace, LabEx Medalis, and Fondation pour la
Recherche Médicale. QM was the recipient of travel grants of Fondation René Touraine and Mitacs Globalink-Campus France. These funding sources had no involvement in study design, interpretation of data and article writing.

\section{Appendix A. Supplementary data}

Supplementary data to this article can be found online at https://doi.org/10.1016/j.actbio.2018.10.011.

\section{References}

[1] E.M. Peters, M.E. Ericson, J. Hosoi, K. Seiffert, M.K. Hordinsky, J.C. Ansel, R. Paus, T.E. Scholzen, Neuropeptide control mechanisms in cutaneous biology: physiological and clinical significance, J. Invest. Dermatol. 126 (9) (2006) 1937-1947.

[2] I.M. Chiu, C.A. von Hehn, C.J. Woolf, Neurogenic inflammation and the peripheral nervous system in host defense and immunopathology, Nat. Neurosci. 15 (8) (2012) 1063-1067.

[3] M. Gingras, J. Bergeron, J. Dery, H.D. Durham, F. Berthod, In vitro development of a tissue-engineered model of peripheral nerve regeneration to study neurite growth, FASEB J. 17 (14) (2003) 2124-2126.

[4] V. Gagnon, D. Larouche, R. Parenteau-Bareil, M. Gingras, L. Germain, F. Berthod, Hair follicles guide nerve migration in vitro and in vivo in tissue-engineered skin, J. Invest. Dermatol. 131 (6) (2011) 1375-1378.

[5] M. Blais, L. Mottier, M.A. Germain, S. Bellenfant, S. Cadau, F. Berthod, Sensory neurons accelerate skin reepithelialization via substance $P$ in an innervated tissue-engineered wound healing model, Tissue Eng. Part A 20 (15-16) (2014) 2180-2188.

[6] Y Shi, H. Inoue, J.C. Wu, S. Yamanaka, Induced pluripotent stem cell technology: a decade of progress, Nat. Rev. Drug Discov. 16 (2) (2017) 115130.

[7] K. Schrenk-Siemens, H. Wende, V. Prato, K. Song, C. Rostock, A. Loewer, J. Utikal, G.R. Lewin, S.G. Lechner, J. Siemens, PIEZO2 is required for mechanotransduction in human stem cell-derived touch receptors, Nat. Neurosci. 18 (1) (2015) 10-16. 
[8] A. Eigentler, S. Boesch, R. Schneider, G. Dechant, R. Nat, Induced pluripotent stem cells from friedreich ataxia patients fail to upregulate frataxin during in vitro differentiation to peripheral sensory neurons, Stem Cells Dev. 22 (24) (2013) 3271-3282.

[9] B.J. Wainger, E.D. Buttermore, J.T. Oliveira, C. Mellin, S. Lee, W.A. Saber, A.J. Wang, J.K. Ichida, I.M. Chiu, L. Barrett, E.A. Huebner, C. Bilgin, N. Tsujimoto, C. Brenneis, K. Kapur, L.L. Rubin, K. Eggan, C.J. Woolf, Modeling pain in vitro using nociceptor neurons reprogrammed from fibroblasts, Nat. Neurosci. 18 (1) (2015) 17-24.

[10] S.M. Chambers, Y. Qi, Y. Mica, G. Lee, X.J. Zhang, L. Niu, J. Bilsland, L. Cao, E. Stevens, P. Whiting, S.H. Shi, L. Studer, Combined small-molecule inhibition accelerates developmental timing and converts human pluripotent stem cells into nociceptors, Nat. Biotechnol. 30 (7) (2012) 715-720.

[11] D. Pre, M.W. Nestor, A.A. Sproul, S. Jacob, P. Koppensteiner, V. Chinchalongporn, M. Zimmer, A. Yamamoto, S.A. Noggle, O. Arancio, A time course analysis of the electrophysiological properties of neurons differentiated from human induced pluripotent stem cells (iPSCs), PLOS One 9 (7) (2014) e103418.

[12] J.W. Blanchard, K.T. Eade, A. Szucs, V. Lo Sardo, R.K. Tsunemoto, D. Williams, P. P. Sanna, K.K. Baldwin, Selective conversion of fibroblasts into peripheral sensory neurons, Nat. Neurosci. 18 (1) (2015) 25-35.

[13] L. Menendez, M.J. Kulik, A.T. Page, S.S. Park, J.D. Lauderdale, M.L. Cunningham, S. Dalton, Directed differentiation of human pluripotent cells to neural crest stem cells, Nat. Protoc. 8 (1) (2013) 203-212.

[14] Y. Maury, J. Come, R.A. Piskorowski, N. Salah-Mohellibi, V. Chevaleyre, M. Peschanski, C. Martinat, S. Nedelec, Combinatorial analysis of developmental cues efficiently converts human pluripotent stem cells into multiple neuronal subtypes, Nat. Biotechnol. 33 (1) (2015) 89-96.

[15] M.J. Caterina, Z. Pang, TRP channels in skin biology and pathophysiology, Pharmaceuticals (Basel) 9 (4) (2016) 77.

[16] L. Germain, M. Rouabhia, R. Guignard, L. Carrier, V. Bouvard, F.A. Auger, Improvement of human keratinocyte isolation and culture using thermolysin, Burns 19 (2) (1993) 99-104.

[17] P.L. Tremblay, F. Berthod, L. Germain, F.A. Auger, In vitro evaluation of the angiostatic potential of drugs using an endothelialized tissue-engineered connective tissue, J. Pharmacol. Exp. Ther. 315 (2) (2005) 510-516.

[18] A. Faroni, S.W. Rothwell, A.A. Grolla, G. Terenghi, V. Magnaghi, A. Verkhratsky, Differentiation of adipose-derived stem cells into Schwann cell phenotype induces expression of P2X receptors that control cell death, Cell Death Dis. 4 (2013) e743.

[19] N. Tzekova, A. Heinen, S. Bunk, C. Hermann, H.P. Hartung, B. Reipert, P. Kury, Immunoglobulins stimulate cultured Schwann cell maturation and promote their potential to induce axonal outgrowth, J. Neuroinflammation 12 (2015) 107.

[20] M. Blais, M. Grenier, F. Berthod, Improvement of nerve regeneration in tissueengineered skin enriched with Schwann cells, J. Invest. Dermatol. 129 (12) (2009) 2895-2900.

[21] M. Zou, S. Li, W.H. Klein, M. Xiang, Brn3a/Pou4f1 regulates dorsal root ganglion sensory neuron specification and axonal projection into the spinal cord, Dev. Biol. 364 (2) (2012) 114-127.

[22] R. Wilson, A.A. Ahmmed, A. Poll, M. Sakaue, A. Laude, M. Sieber-Blum, Human peptidergic nociceptive sensory neurons generated from human epidermal neural crest stem cells (hEPI-NCSC), PLOS One 13 (6) (2018) e0199996.

[23] F.J. Naves, J.J. Huerta, O. Garcia-Suarez, N. Urdangaray, I. Esteban, M.E. Del Valle, J.A. Vega, Distribution of immunoreactivity for cytoskeletal (microtubule, microtubule-associated, and neurofilament) proteins in adult human dorsal root ganglia, Anat. Rec. 244 (2) (1996) 246-256.

[24] P.F. Moskowitz, M.M. Oblinger, Sensory neurons selectively upregulate synthesis and transport of the beta III-tubulin protein during axonal regeneration, J. Neurosci. 15 (2) (1995) 1545-1555.

[25] M.V. Rao, M.K. Houseweart, T.L. Williamson, T.O. Crawford, J. Folmer, D.W. Cleveland, Neurofilament-dependent radial growth of motor axons and axonal organization of neurofilaments does not require the neurofilament heavy subunit (NF-H) or its phosphorylation, J. Cell Biol. 143 (1) (1998) 171-181.

[26] A.J. Clark, M.S. Kaller, J. Galino, H.J. Willison, S. Rinaldi, D.L.H. Bennett, Cocultures with stem cell-derived human sensory neurons reveal regulators of peripheral myelination, Brain 140 (4) (2017) 898-913.

[27] L. Riol-Blanco, J. Ordovas-Montanes, M. Perro, E. Naval, A. Thiriot, D. Alvarez, S. Paust, J.N. Wood, U.H. von Andrian, Nociceptive sensory neurons drive interleukin-23-mediated psoriasiform skin inflammation, Nature 510 (7503) (2014) 157-161.

[28] S.M. Ostrowski, A. Belkadi, C.M. Loyd, D. Diaconu, N.L. Ward, Cutaneous denervation of psoriasiform mouse skin improves acanthosis and inflammation in a sensory neuropeptide-dependent manner, J. Invest. Dermatol. 131 (7) (2011) 1530-1538. 


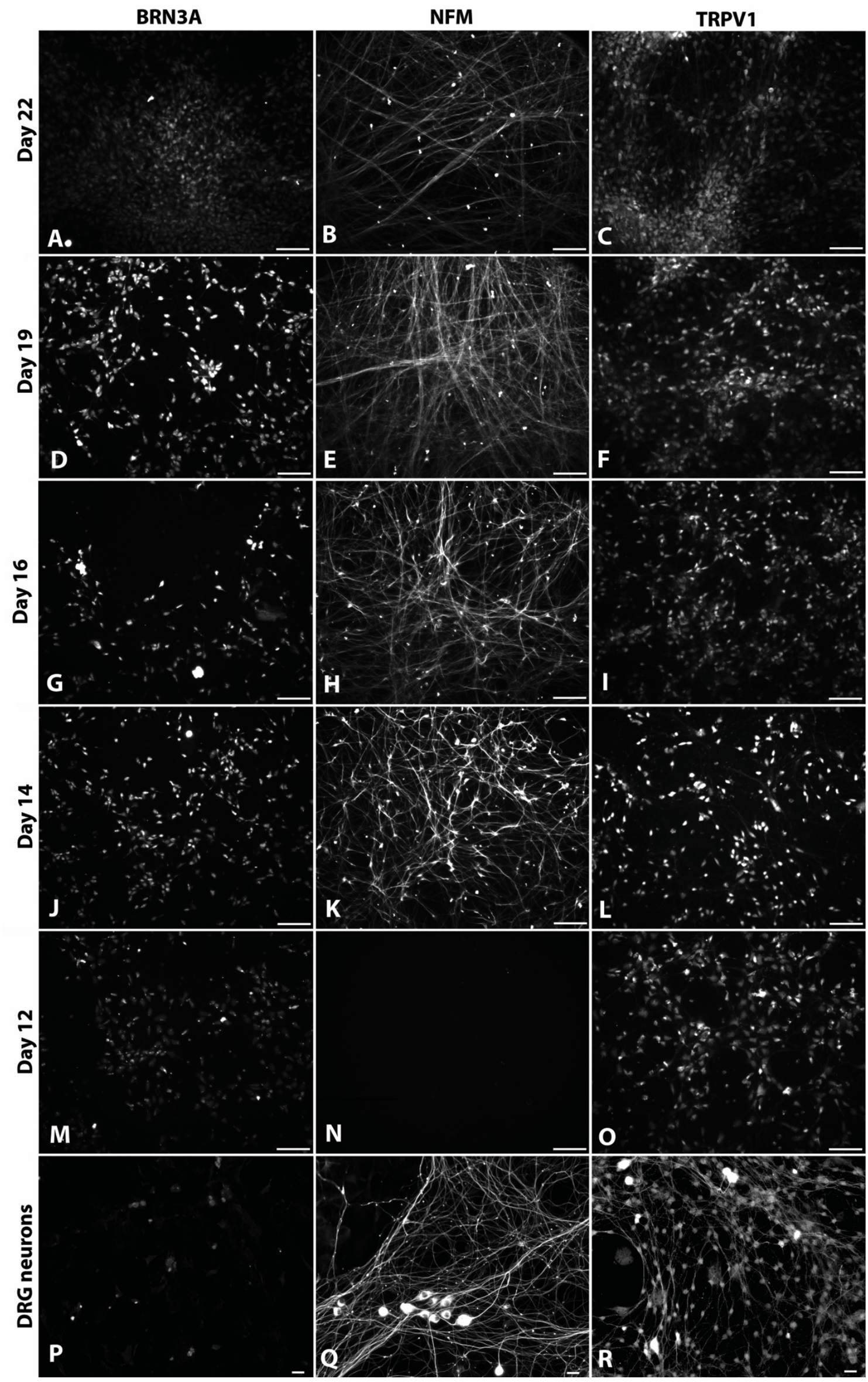


Figure S1 | Characterization of the kinetic of neuronal marker expression in iPSC-derived neurons over 22 days of maturation, compared with mouse DRG neurons

BRN3A, Neurofilament M (NFM) and TRPV1 were stained with specific antibodies after 12 to 22 days of iPSC differentiation into sensory neurons (A-O) compared to mouse DRG neurons (P-R). Scale bar: $50 \mu \mathrm{m}$.
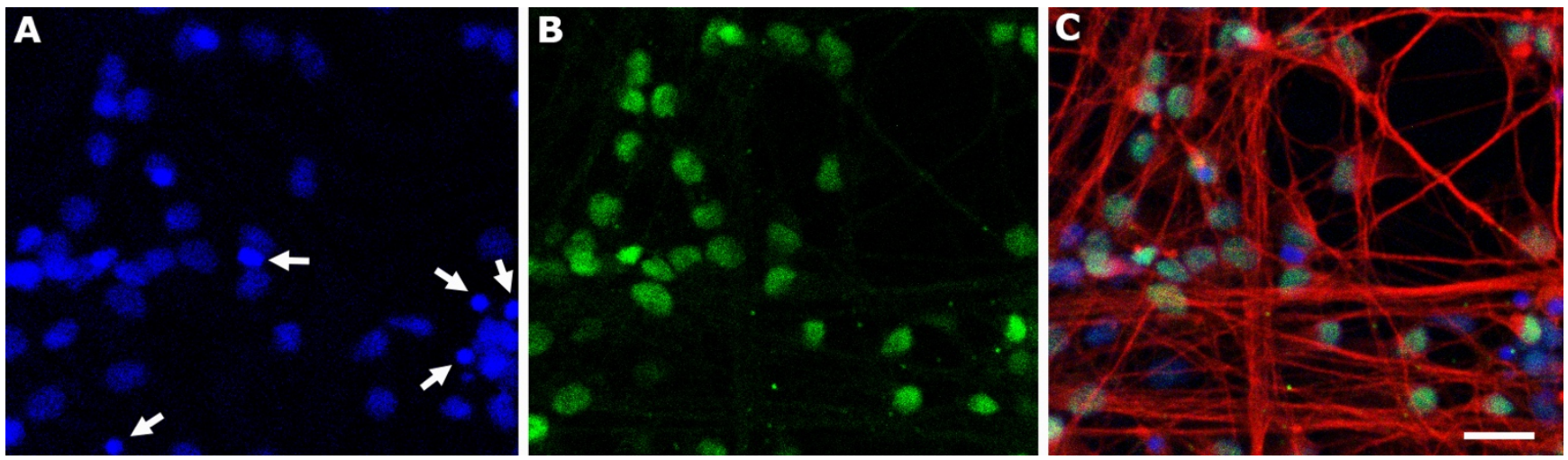

Figure S2 | Quantification by immunocytochemistry of BRN3A/ $\beta$ III Tubulin-positive iPSC-derived neurons

The proportion of iPSC successfully differentiated into neurons was assessed after staining with BRN3A ( $B$, in green) and $\beta$ III Tubulin ( $C$, in red) compared to the total numer of Dapi-positive cells ( $A$, in blue) of cells cultured for 18 days in 24-well plates coated with poly-D-lysine. The white arrows in $A$ indicates cells that don't express the neuronal markers in B and C. C is a merge image of A and B in addition to $\beta$ III Tubulin staining. Scale bar in $C=20 \mu \mathrm{m}$.
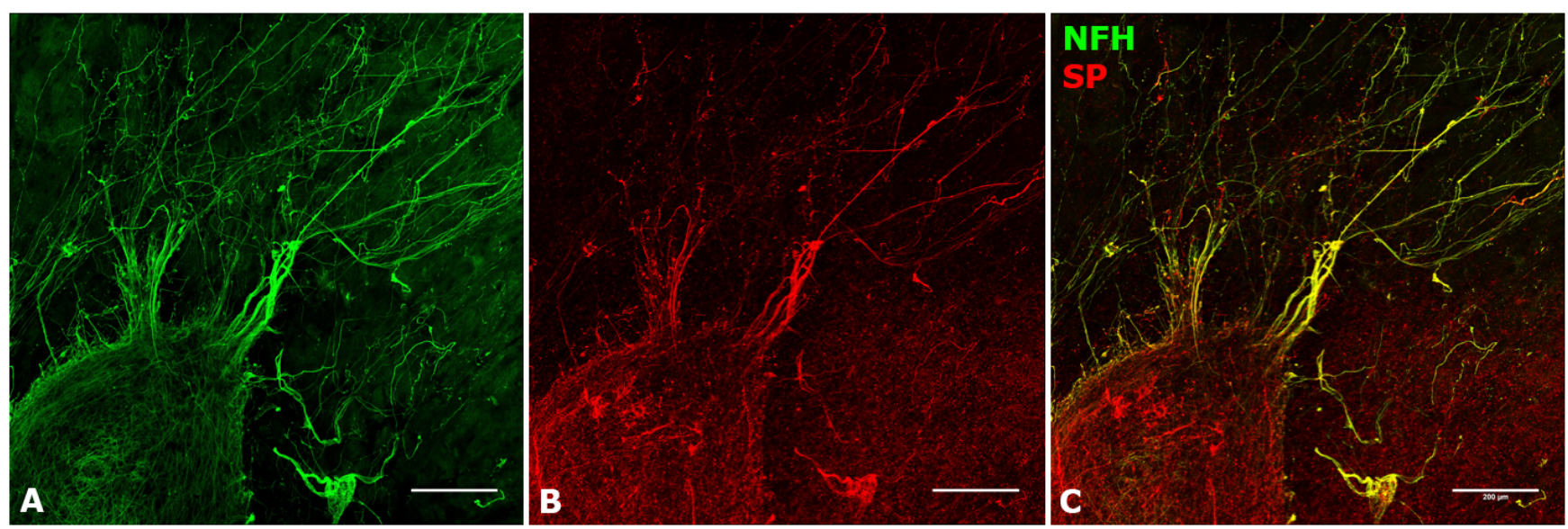

Figure S3 | Characterization by immunofluorescence of the expression of Substance P in neurofilament $\mathbf{H}$-positive iPSC-derived neurons cultured in 3D for 49 days

The iPSC-derived neurons were cultured in the fibroblast-populated sponge for 49 days and pictures were taken from an above view. Most of the NFH-positive nerve fibers (in green in A and C) expressed by iPSC-derived neurons were also positive for SP (in red in B and C). Scale bar $200 \mu \mathrm{m}$. 


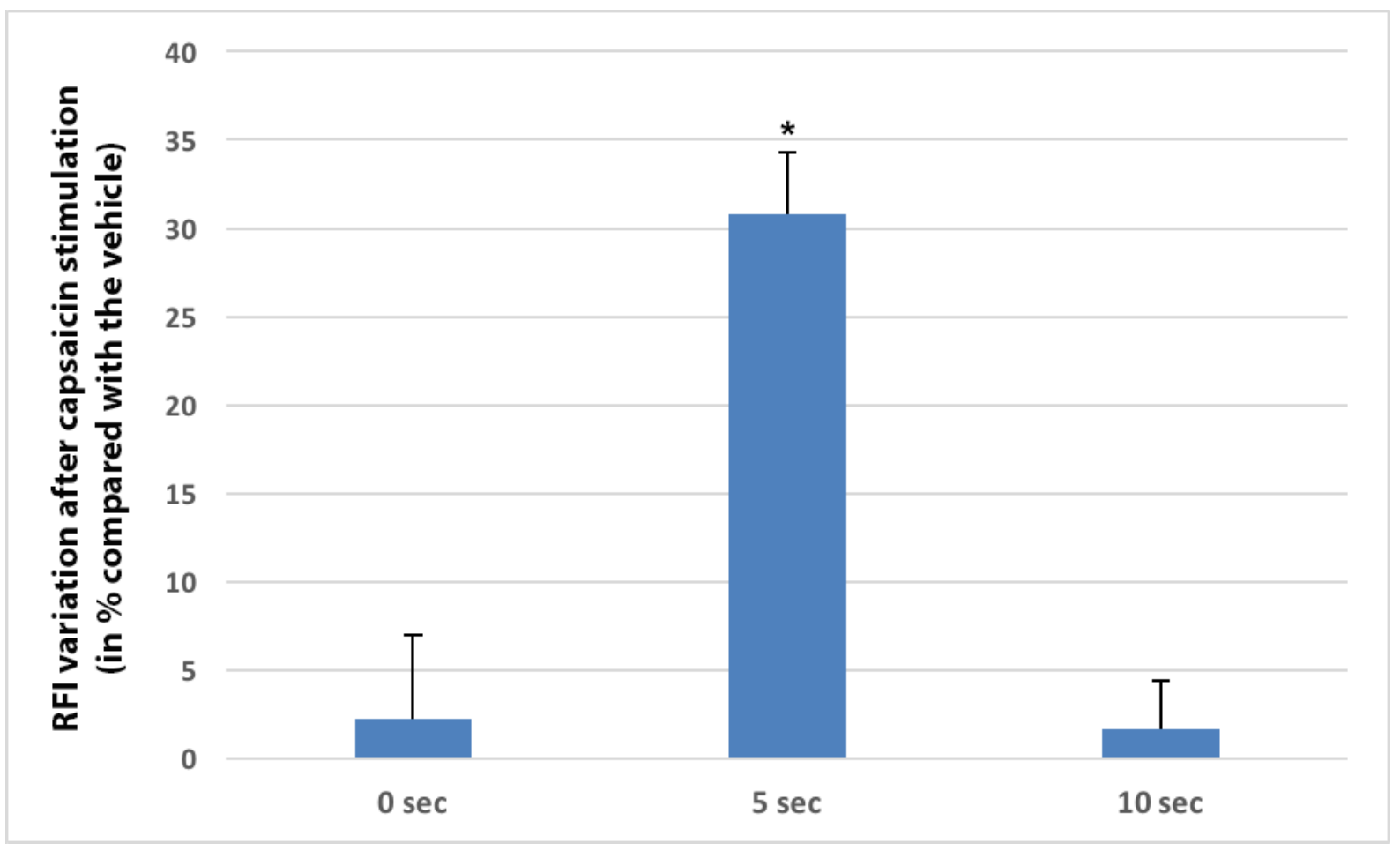

Figure S4 | Characterisation of iPSC-derived neuron excitability upon TRPV1 agonist stimulation by calcium quantification with Fura-2

Calcium flux was determined according to the manufacturer's instructions (Fura-2 no wash calcium assay kit, Abcam). Quantification of the Fura-2 ratiometric dye fluorescence induced by intracellular calcium content was performed using a Varioskan microplate reader (Thermo scientific) before and 5 and 10 seconds after stimulation with $10 \mu \mathrm{M}$ capsaicin of iPSC-derived neurons matured for 19 days. Results were expressed as the percentage of the relative fluorescence intensity (RFI) obtained with the capsaicin treatment compared to the RFI obtained with an incubation of the same sample with the vehicle $(100 \mu$ l DME with $0.99 \%$ ethanol vol:vol). No calcium increase was observed when fibroblasts were stimulated with $10 \mu \mathrm{M}$ capsaicin (data not shown). Data were expressed in relative fluorescence units (RFI) as mean \pm standard deviation $\left({ }^{*} p<0.0001, n=6\right)$. 